\title{
Ascorbic Acid Increases the Number of Dopamine Neurons In Vitro and in Transplants to the 6-OHDA-Lesioned Rat Brain
}

\author{
V. Bagga,* S. B. Dunnett,* and R. A. Fricker-Gates $\dagger$ \\ *Brain Repair Group, School of Biosciences, Cardiff University, Cardiff, Wales, UK \\ $†$ Schools of Medicine and Life Sciences, and Institute for Science and Technology in Medicine, \\ Keele University, Keele, Staffordshire, UK
}

\begin{abstract}
The inadequate survival of dopamine neurons following intracerebral transplantation is in part attributed to the generation of reactive oxygen species and subsequent oxidative stress. To address this, we investigated whether the antioxidant ascorbic acid (vitamin C) had any effect on the yields of dopamine neurons derived from E14 rat ventral mesencephalic cells in vitro and in grafts. Following in vitro differentiation in medium containing ascorbic acid at concentrations ranging from 20 to $100 \mu \mathrm{M}$, significantly more neurons were immunopositive for the marker of mesencephalic dopamine neurons, tyrosine hydroxylase (TH), when compared to standard differentiation conditions containing no ascorbic acid. Mesencephalic cell suspensions supplemented with $100 \mu \mathrm{M}$ ascorbic acid were also transplanted into unilateral 6-OHDA-lesioned rats and behavioral rotation was assessed at 2, 4, and 6 weeks posttransplantation. Grafts pretreated with ascorbic acid contained significantly more surviving dopamine neurons compared to nontreated grafts. However, no significant difference in rotation score was observed, with both groups showing a reversal and overcompensation of rotational bias. In addition, no evidence of neurogenesis of nigral dopamine neurons was observed in transplant groups. While the increased number of dopamine neurons observed in our study following ascorbic acid treatment may reflect a selective survival effect, our in vitro results suggest that ascorbic acid may act to increase the number dopamine neurons, both in culture and following transplantation, by stimulating dopaminergic differentiation of neural precursors from the fetal ventral mesencephalon.
\end{abstract}

Key words: Ascorbic acid; Dopaminergic neurons; Neuronal survival; Parkinson's disease; Transplantation; Oxidative stress

\section{INTRODUCTION}

Transplantation of embryonic mesencephalic tissue into the dopamine-depleted striatum has shown clear functional improvements by ameliorating behavioral deficits in a variety of animal models $(3,4,8,26,34)$. The extent of functional recovery is however limited, with grafts unable to reverse all lesion-induced behavioral abnormalities. This limited recovery may in part relate to poor graft survival because only $5-10 \%$ of dopaminergic neurons typically survive transplantation (15). This low survival of dopamine neurons following transplantation means that for sufficient functional benefits to be achieved in Parkinson's disease patients, transplantation of mesencephalic tissue from four to eight human embryos is required per side of the brain (11). The requirement for large quantities of human embryonic tissue for each patient makes widespread clinical delivery impractical; therefore, increasing dopamine graft survival needs to be achieved if neuronal replacement therapies are going to succeed $(10,11)$.

In addition, the appearance of graft-induced dyskinesias in some patients receiving ventral mesencephalic transplants partially has been attributed to poor dopamine neuron survival, and the consequent "patchiness" of dopaminergic reinnervation within the caudate and putamen where the transplants are placed $(21,27)$. Clearly, if the survival of dopamine neurons can be increased in vivo, then clinicians will have far more control on the transplant procedure, including the targeting of optimal sites for graft placement, and the ability to restore full and homogenous dopaminergic innervation throughout the striatum.

One possible reason for the poor survival of dopamine neurons may be because of oxidative stress caused by free radicals, a mechanism that has been implicated in the death of substantia nigra dopamine neurons in Parkinson's disease $(16,29,33)$. It is thought that oxida- 
tive stress caused by cellular trauma during dissection and tissue preparation is one of the mechanisms contributing to poor neuronal survival, potentially by inducing apoptosis in transplanted neurons (11,39). Removing cells from low oxygen environments and exposing them to atmospheric oxygen levels of $20 \%$ during the dissection procedure may also promote oxidative stress and therefore decrease dopamine neuron survival. This might explain why increased dopamine survival is observed when mesencephalic tissue is cultured in lowered oxygen levels representative of those levels found in developing tissues $(13,35,36)$. The neuroprotective effects of antioxidants on isolated mesencephalic cells also provide convincing evidence that the cell death of dopamine neurons is mediated via oxidative stress $(13,25)$. Supplementing mesencephalic cell suspensions with glutathione shows increased survival of dopamine neurons (25). Conversely, inhibition of glutathione synthesis by using L-buthionine sulfoximine results in a significant reduction in the survival of these cells (19). Dopamine neurons in glutathione-depleted cultures can be rescued by treating cultures with lazaroids (19), which inhibit lipid peroxidation and the formation of free radicals, increase dopamine survival in vitro (17), increase cell viability of dissociated mesencephalic cells, and importantly increase dopamine neuron survival in grafts (28). The increased dopamine survival in grafts following lazaroid treatment is reflected in amelioration of rotational bias in unilateral lesioned rats, with faster recovery of rotational asymmetry being observed compared to rats receiving nontreated grafts (28). Interestingly, grafts pretreated with glutathione alone do not show increased survival of dopamine neurons and attenuation of rotational behavior when compared to controls (25). However, in a recent study by Agrawal et al. (2), increased dopaminergic neuron survival and reduction in rotation asymmetry were seen when glutathione was combined with ascorbic acid. However, that study (2) raised several ambiguities that need to be addressed. One of the major issues is that the authors show an increase in the number of dopaminergic neurons in the substantia nigra when dopaminergic neurons are cotransplanted with antioxidants into the striatum of 6-OHDA-lesioned rats. The authors suggest that this increase in nigral dopamine neurons may be due to stimulation of neurogenesis in the substantia nigra. However, it is equally plausible that the results simply reflect incomplete 6-OHDA lesioning of the medial forebrain bundle. If this is the case, the behavioral observations reported by the authors following dopamine neuron transplantation may not be attributable to the antioxidant treatment per se, but rather to relative sparing of the primary lesion targets.

In this study, we investigated whether the antioxidant effects of ascorbic acid could increase dopamine neuron survival both in vitro and in grafts transplanted into the unilateral 6-OHDA-lesioned rat brain. Ascorbic acid was the only antioxidant used because previous reports have shown that the majority of dopamine cell death occurs over the first $24 \mathrm{~h}$ from cell dissociation, and this coincides with rapid ascorbic acid depletion in cultured cells (23). Not only does this study evaluate the effect of ascorbic acid alone on dopaminergic neurons, but it also gives the opportunity to clarify the ambiguous results presented by Agrawal and colleagues.

\section{MATERIALS AND METHODS}

\section{Subjects}

In vivo studies were conducted in young adult female rats of the Sprague-Dawley strain (Harlan Olac, Bicester, UK). Animals were housed in groups of three to four rats/cage on a natural 12:12 h light dark cycle and with ad libitum access to food and water throughout. Fetal tissues for cell culture or grafts were derived from E14 fetuses (crown-rump length $=11 \mathrm{~mm}$ ) obtained from pregnant female rats of the same out-bred strain. All studies were conducted in accordance with full ethical appraisal and licenses under the UK Animals (Scientific Procedures) Act 1986.

\section{Tissue Dissection and Cell Suspension}

Pregnant donors were killed by decapitation under general anesthesia, and the fetuses removed by cesarean section. The ventral mesencephalon (VM) was dissected and pooled from all donors in a litter. Dissected tissue was enzymatically digested using a solution of $0.1 \%$ trypsin (Worthington, Lakewood, NJ, USA) and $0.05 \%$ DNase (Sigma, Poole, Dorset, UK), at $37^{\circ} \mathrm{C}$ for $20 \mathrm{~min}$. After two rinses in HBSS the tissue was dissociated into a single suspension by mechanical trituration using a $200-\mu \mathrm{l}$ Gilson pipette. Cell counts and percentage viable cells were assessed by trypan blue exclusion in a hemocytometer. Typically, one VM generated $1 \times 10^{6}$ cells.

\section{In Vitro Studies}

Cell Viability. Dissociated VM tissue was incubated at $37^{\circ} \mathrm{C}, 5 \% \mathrm{CO}_{2}$ for $1 \mathrm{~h}$ in $\mathrm{HBSS}$ supplemented with different concentrations of ascorbic acid (Sigma). Cell viability was then assessed by trypan blue exclusion as above.

Cell Differentiation. Single cells that had not been pretreated with ascorbic acid were dry plated at a density of 50,000 cells in $30 \mu \mathrm{l}$ ascorbic acid-free differentiation medium onto glass coverslips coated with $100 \mu \mathrm{l} / \mathrm{ml}$ poly-lysine (Sigma) and $10 \mu \mathrm{l} / \mathrm{ml}$ laminin (Sigma) in individual wells of $24-w e l l$ plates. After $4-16 \mathrm{~h}$ to allow for attachment, $0.5 \mathrm{ml}$ differentiation medium containing ascorbic acid was added to each well and cultures 
were allowed to differentiate over 7 days at $37^{\circ} \mathrm{C}$ in $5 \%$ $\mathrm{CO}_{2}$. Wells were supplemented every alternate day with $0.5 \mathrm{ml}$ fresh differentiation medium. The differentiation medium consisted of Neurobasal medium (Invitrogen) supplemented with 1\% B27 (Gibco), 1\% antibiotic/antimycotic solution (Invitrogen), $30 \mathrm{mM}$ glucose (Sigma), $1 \mathrm{mM}$ glutamine (Invitrogen), $50 \mathrm{ng} / \mathrm{ml}$ bovine serum albumin (Sigma), 1\% fetal calf serum (Invitrogen), and ascorbic acid (Sigma) at concentrations ranging from 1 to $5000 \mu \mathrm{M}$. All in vitro experiments were repeated three times and data were expressed as mean \pm SEM.

Immunocytochemistry. Coverslips were fixed with $4 \%$ paraformaldehyde at $4^{\circ} \mathrm{C}$ for $20 \mathrm{~min}$. After three rinses in $0.02 \mathrm{M}$ potassium-buffered phosphate saline (KPBS), cells were permeabilised with $100 \%$ ethanol for 2 min. Following three rinses in KPBS, coverslips were preincubated in 5\% normal goat serum (NGS) for $1 \mathrm{~h}$ at $4^{\circ} \mathrm{C}$. Coverslips were then incubated with primary antibodies to $\beta$-III tubulin (1:400, mouse monoclonal, Sigma) and tyrosine hydroxylase $(1: 1000$, rabbit polyclonal, Chemicon) in $1 \%$ NGS for $16 \mathrm{~h}$ at $4^{\circ} \mathrm{C}$. Following three rinses in KPBS, coverslips were incubated with mixed Alexa 488 goat anti-mouse and Alexa 594 goat anti-rabbit secondary antibodies (both 1:200, Molecular Probes, Eugene, OR, USA) in $1 \%$ NGS, for $2 \mathrm{~h}$ in the dark. Coverslips were rinsed with KPBS and then treated with $1.25 \mu \mathrm{l} / \mathrm{ml}$ of $0.2 \mathrm{mg} / \mathrm{ml}$ Hoechst (Fisher, Acros Organics, Loughborough, UK) for $4.5 \mathrm{~min}$. Following three final KPBS rinses, coverslips were mounted onto uncoated glass microscope slides using a poly vinyl alcohol1,4-diazabicyclo[2,2,2]octane (PVA-DABCO) mountant and stored at $4{ }^{\circ} \mathrm{C}$.

Cells were visualized under UV fluorescence using a Leitz stereomicroscope. Initially Hoechst-stained nuclei were identified to obtain a total cell count within a grid randomly placed on the coverslips and viewed under $50 \times$ magnification. Each cell immunopositive for Hoechst was checked for expression of $\beta$-tubulin under fluorescence. Cells immunopositive for $\beta$-tubulin were also checked for expression of TH. Counts were made on at least five fields per coverslip, including a minimum of 250 cells, and on replicates of three to four coverslips per treatment.

\section{In Vivo Studies}

Rats were divided into five groups, as specified in Table 1. All surgery was undertaken using a Kopf 900 frame with the rats maintained under gaseous isoflurane $\left(2-5 \%\right.$ in $\left.2: 1 \mathrm{O}_{2} / \mathrm{N}_{2}\right)$ anesthesia. After each surgical session, rats were sutured and injected with $5 \mathrm{ml} 0.9 \%$ saline/glucose solution to prevent dehydration. The drinking water was supplemented with paracetamol for the following $48 \mathrm{~h}$ and animals were carefully monitored postsurgery. All animals were allowed to recover for at least 10 days before behavioral testing commenced.

6-OHDA Lesions. Animals received unilateral stereotaxic injections of $3 \mu \mathrm{l}$ of $4 \mu \mathrm{g} / \mu \mathrm{l}$ of 6-hydroxydopamine hydrobromide (6-OHDA, Sigma) dissolved in physiological saline containing $0.01 \%$ ascorbic acid. Infusions were delivered over 3 min via a 30-gauge stainless steel cannula targeted into the right medial forebrain bundle $(\mathrm{A}=-4.4 \mathrm{~mm}$ anterior to bregma; $\mathrm{L}=-1.8 \mathrm{~mm}$ lateral to the midline, $\mathrm{V}=-7.8 \mathrm{~mm}$ ventral to dura; with the incisor bar set $-2.3 \mathrm{~mm}$ below the interaural line). The cannula was left in place for a further $2 \mathrm{~min}$ for diffusion before being slowly removed, and the wound cleaned and sutured.

Transplantation. VM cell suspensions were prepared as for the in vitro experiments (see above). Once dissociated, half the VM cells were resuspended in transplant medium (DMEM/F12 (Invitrogen) supplemented with $0.6 \%$ glucose (Sigma)) containing $100 \mu \mathrm{M}$ ascorbic acid for transplantation; the remaining cells were resuspended in transplant medium alone. Cell suspensions were grafted into the right neostriatum by stereotaxic injection of 500,000 cells (containing approximately half of one VM, i.e., 22,000 putative dopamine neurons) $(7,18)$, in $4 \mu \mathrm{l}$, at $\mathrm{A}=0.8 \mathrm{~mm}, \mathrm{~L}=-3.0 \mathrm{~mm}, \mathrm{~V}=-5.0$ $\mathrm{mm}$ and $-4.5 \mathrm{~mm}(2 \mu \mathrm{l}$ at each depth) using a $10-\mu \mathrm{l}$ Hamilton microsyringe over 4 min. A further 4 min was allowed for diffusion prior to syringe removal, and the wound was then cleaned and sutured. A second group of animals received $4 \mu \mathrm{l}$ injections of $100 \mu \mathrm{M}$ ascorbic acid alone, dissolved in transplant medium. All animals were allowed to recover for at least 10 days before behavioral testing commenced.

Rotation. Amphetamine-induced rotational behavior was assessed at regular intervals postlesion and transplantation in a bank of automated rotation bowls (diameter of $32 \mathrm{~cm}$; height of $14 \mathrm{~cm}$ ) modeled after the design of Ungerstedt and Arbuthnott (37). Rats were placed in the bowls and allowed to habituate for $10 \mathrm{~min}$ before IP injection with $2.5 \mathrm{mg} / \mathrm{kg}$ methamphetamine $\mathrm{HCl}$ (Sigma). Rats were monitored for $90 \mathrm{~min}$ with the net ipsilateral rotation (total right - total left $360^{\circ}$ turns) over the full 90 min used as the primary dependent variable.

\section{Histology}

After behavioral testing had been completed, animals were terminally injected with $0.5 \mathrm{ml}$ Euthatal and transcardially perfused with $100 \mathrm{ml}$ phosphate-buffered saline (PBS, $\mathrm{pH}$ 7.4) followed by $250 \mathrm{ml} 4 \%$ paraformaldehyde (PFA, pH 7.4). The brains were removed and postfixed in PFA for a further $24 \mathrm{~h}$ before being placed in PBS containing 25\% sucrose overnight for sectioning. Coronal sections were cut on a sledge microtome at 40 
Table 1. Rat Allocation to Groups

\begin{tabular}{llcccc}
\hline & & & & & Ascorbic \\
Name & \multicolumn{1}{c}{ Group } & $n$ & $\begin{array}{c}\text { Nigrostratal } \\
\text { Lesion }\end{array}$ & $\begin{array}{c}\text { Nigral } \\
\text { Graft }\end{array}$ & $\begin{array}{c}\text { Acid } \\
(100 \mu \mathrm{M})\end{array}$ \\
\hline $\mathrm{C}$ & intact controls & 6 & - & - & - \\
$\mathrm{L}$ & lesion alone & 8 & + & - & - \\
$\mathrm{L} / \mathrm{AA}$ & lesion + AA alone & 8 & + & - & + \\
L/VMg & lesion + VM graft & 9 & + & + & - \\
L/VMg+AA & lesion + VM graft $+100 \mu \mathrm{MAA}$ & 10 & + & + & + \\
\hline
\end{tabular}

$\mathrm{L}$, nigrostriatal lesion; VMg, ventral mesencephalic tissue grafts; +AA, graft preparation with addition of $100 \mu \mathrm{M}$ ascorbic acid.

$\mu \mathrm{m}$ and stored at $4{ }^{\circ} \mathrm{C}$ in Tris-buffered $0.9 \%$ saline (TBS, $\mathrm{pH}$ 7.4), containing $0.5 \%$ sodium azide. A $1: 6$ series of brain sections was quenched with $10 \%$ hydrogen peroxide and $10 \%$ methanol in distilled water for 5 min followed by three 10-min washes in TBS. Sections were then blocked in TBS containing $0.2 \%$ Triton X-100 (TXTBS) and 3\% normal goat serum (NGS) for $60 \mathrm{~min}$. Without washing, brain sections were incubated overnight at room temperature, or over 2 nights at $4^{\circ} \mathrm{C}$ in TXTBS containing the primary rabbit anti-tyrosine hydroxylase (TH) antibody at a concentration of 1:1000 (Chemicon, Temecula, CA) in 1\% NGS. After three 10min washes with TBS, sections were incubated at room temperature for $3 \mathrm{~h}$ in the secondary biotinylated goat anti-rabbit antibody at a concentration of 1:200 (DAKO, Denmark) in TBS. Sections were washed in TBS before being incubated for a further $2 \mathrm{~h}$ at room temperature in streptavidin-biotin complex (DAKO) in TBS with $1 \%$ NGS. Following washes in TBS and Tris-Non-Saline (distilled water containing $0.6 \%$ trizma base), TH-positive cells in the substantia nigra were visualized by reaction with Vector SG kit (DAKO). Sections were mounted on gelatinized glass slides, air dried overnight and dehydrated in an ascending series of alcohols, cleared in xylene, and coverslipped with DPX.

\section{Histological Analyses}

The total numbers of dopaminergic neurons surviving in VM transplants were estimated by counting all THpositive cells in every sixth $40-\mu \mathrm{m}$ coronal brain section through the grafts at a magnification of $200 \times$ using a Leitz Dialux 22 microscope. Only those TH cells that were clearly identified and that possessed dendritic processes were counted. The average TH cell diameter was then calculated by measuring at least 50 random $\mathrm{TH}$ positive cells using an Olympus BX50 microscope and an Olympus C.A.S.T grid system. The total number of $\mathrm{TH}$ cells present in each brain was estimated using the Abercrombie correction formula (1).

TH fiber outgrowth from the grafts was visualized using the Leitz stereomicroscope at a magnification of $100 \times$. The density of outgrowth was assessed by counting the number of fibers that crossed a $100-\mu \mathrm{m}$ vertical line at regular $100-\mu \mathrm{m}$ intervals perpendicular to the horizontal radial from the grafts. Measurements were taken in a single focal section at the center of the graft, starting at the edge of the graft moving medially until no more fibers were visible or until the ventricular margin of the striatum was reached.

\section{Statistical Analyses}

Quantitative measures of rotation, TH-positive cell survival, and fiber outgrowth were undertaken by multifactorial analysis of variance (ANOVA) using the Genstat v7.2 statistical package (Rothampstead, Oxon) with post hoc multiple comparisons by the Newman-Keuls test.

\section{RESULTS}

\section{Effect of Ascorbic Acid on Ventral Mesencephalic} Cell Viability

The effects of ascorbic acid concentration on VM cell viability are shown in Figure 1. Ascorbic acid concentrations ranging from 1 to $1000 \mu \mathrm{M}$ showed no significant effects on total cell viability, neither increasing nor decreasing the percent of viable cells when compared with control cultures. However, ascorbic acid induced a significant decrease in cell viability at the highest two concentrations of 2.5 and $5 \mathrm{mM}$ used $[F(10,32)=10.55$, $p<0.001]$.

\section{Effect of Ascorbic Acid on the Survival of VM Cells In Vitro}

Cells isolated from E14 rat ventral mesencephalic tissue were plated immediately following dissection, in media containing different concentrations of ascorbic acid ranging from $1 \mu \mathrm{M}$ to $5 \mathrm{mM}$. After 1 day in vitro, morphological analysis revealed the presence of both neurons and astrocytes in the cultures (Fig. 2). No significant difference in survival of differentiated neurons 


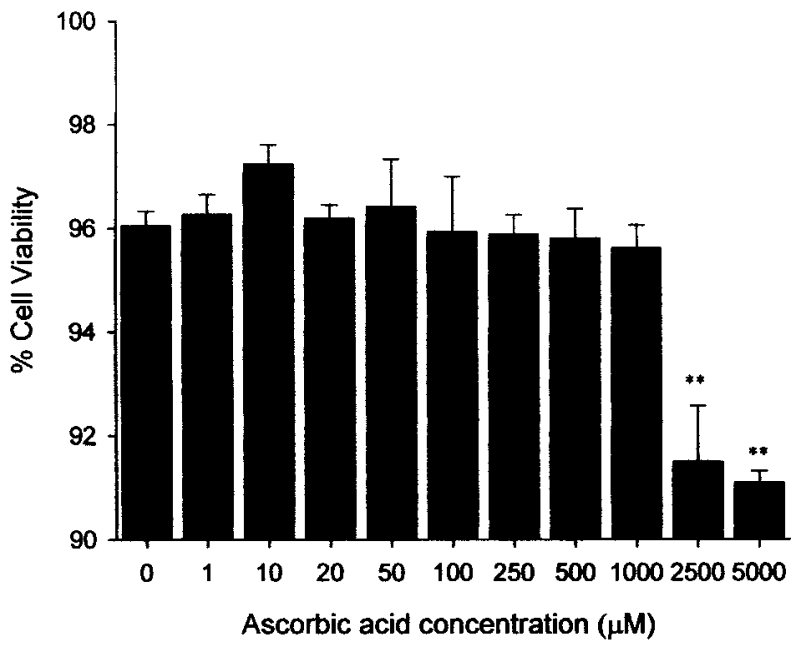

Figure 1. Effects of ascorbic acid on total cell viability of dissociated $\mathrm{VM}$ tissue, incubated at $37^{\circ} \mathrm{C}, 5 \% \mathrm{CO}_{2}$ for $1 \mathrm{~h}$, in HBSS supplemented with different concentrations of ascorbic acid. Cell viability was then assessed by the trypan blue exclusion. A significant effect of ascorbic acid concentration on cell death is observed $(p<0.001)$, with cells exposed to concentrations of 2500 and $5000 \mu \mathrm{M}$ showing significantly decreased cell viability when compared to all other concentrations $(p<$ 0.01). Ascorbic acid at concentrations ranging from 1 to 1000 $\mu \mathrm{M}$ are not significantly different to control $(0 \mu \mathrm{M})$. Data expressed as mean \pm SEM across three separate experiments. $* * p<0.01$ versus $0 \mu \mathrm{M}$.

or astrocytes was observed at low ascorbic acid concentrations $(1-250 \mu \mathrm{M})$. Ascorbic acid-induced cell death of both neurons and astrocytes was evident at higher doses $(500-5000 \mu \mathrm{M})$ and cell cultures failed to become established (Fig. 2M-P).

\section{Effect of Ascorbic Acid on Neuronal Yield}

At ascorbic acid concentrations ranging from 1 to $250 \mu \mathrm{M}$ there was no significant difference in proportion of $\beta$-III tubulin-positive neurons when compared to controls, with neuronal yield ranging from $61 \%$ to $70 \%$ (Fig. 3A). However, with higher concentrations of ascorbic acid neuronal yield was significantly reduced $[F(7,104)=17.36, p<0.001]$, with cultures treated with $500 \mu \mathrm{M}$ ascorbic acid and above showing a significant reduction in the generation of neurons when compared to control cultures.

\section{Effect of Ascorbic Acid on the Number of Dopamine Neurons}

In addition to examining the neuronal yield of primary VM cells, the effect of ascorbic acid concentration on the expression of TH-positive neurons was also assessed. Cells exposed to concentrations of $20-250 \mu \mathrm{M}$ generated significantly more $\mathrm{TH}$-immunopositive neu- rons when compared to controls (Fig. 2A-L), whereas cells treated with $500 \mu \mathrm{M}$ ascorbic acid or above generated significantly fewer TH-positive neurons compared to the low dose and control conditions $[F(7,104)=$ 51.77, $p<0.001$ ] (Fig. 3B).

\section{Effect of Ascorbic Acid on the Number} of TH-Positive Neurons in Grafts

Grafts of dopamine neurons into the dopaminedepleted rat striatum were clearly identified along with a characteristic halo of dopamine innervation (Fig. 4A). Grafts treated with or without ascorbic acid both contained numerous TH-positive neurons, which projected extensively throughout the grafted site (Fig. 4B, C). Analysis of the data showed that VM grafts alone contained approximately 1,700 TH-positive neurons, equating to $7.7 \%$ survival of the 22,000 putative dopamine neurons that would have been implanted in the suspension of 500,000 cells or one half of a ventral mesencephalon (including A8, A9, and A10 nuclei) (7,18). VM grafts containing $100 \mu \mathrm{M}$ ascorbic acid contained significantly higher numbers of TH-positive neurons when compared to grafts of VM cells only, with approximately 2,300 TH-positive cells per graft, equating to a $13.5 \%$ survival of the implanted dopamine neurons $(p<$ 0.05) (Fig. 4D).

\section{Effect of Ascorbic Acid on Graft Fiber Outgrowth}

As expected, the number of fiber projections observed decreased significantly with increasing distance from the graft site (Fig. 5). However, there was no significant difference in the extent of TH fiber outgrowth observed between VM grafts that were or were not treated with ascorbic acid $[F(1,159)=1.53$, n.s $]$ (Fig. 5).

\section{Effect of Ascorbic Acid on Graft-Derived Recovery of Rotation}

The rates of rotation in the five experimental groups following lesion and transplantation surgeries are shown in Figure 6. As expected, the control group showed no net rotation, the two lesion groups showed stable ipsilateral rotation at a rate of $\sim 10$ ipsilateral turns per minure, and the graft groups showed significant recovery and overcompensation to net contralateral turning 4 and 6 weeks after transplantation [Groups, $F(4,167)=12.66$; Tests, $F(3,167)=15.23$; Group $\times$ Tests, $F(12,167)=$ 6.09; all $p<0.001]$. Critically, however, there were no significant differences between the two graft groups prepared with and without $100 \mu \mathrm{M}$ ascorbic acid, or between the two lesion groups treated with and without ascorbic acid (all post hoc comparisons n.s.).

\section{DISCUSSION}

In an attempt to increase the survival of dopaminergic neurons in grafts of ventral mesencephalic tissue, we 


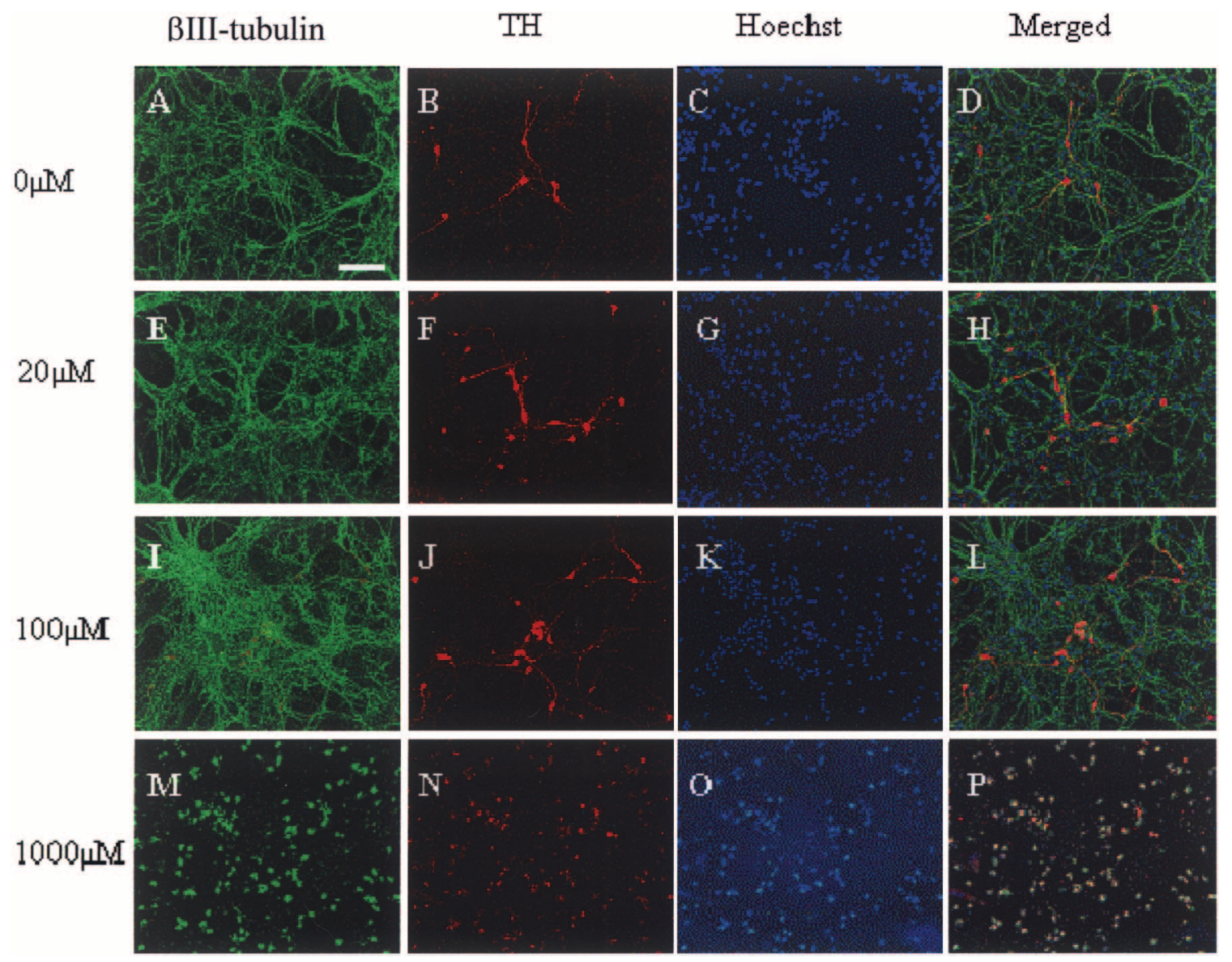

Figure 2. Fluorescent immunocytochemistry of $\beta$-III tubulin-positive neurons (green) and TH-positive neurons (red) with Hoechst counterstain (blue). More TH-positive neurons are observed at $20 \mu \mathrm{M}(\mathrm{F})$ and $100 \mu \mathrm{M}(\mathrm{J})$ ascorbic acid when compared with controls (B). At $1000 \mu \mathrm{M}$, ascorbic acid-induced cytotoxicity was observed (M-P). Scale bar: $100 \mu \mathrm{m}$.

A.

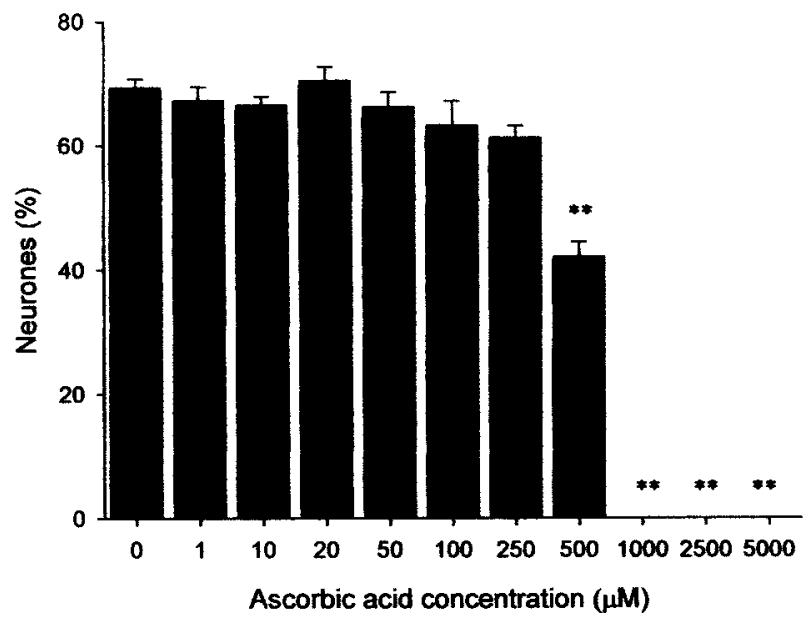

B.

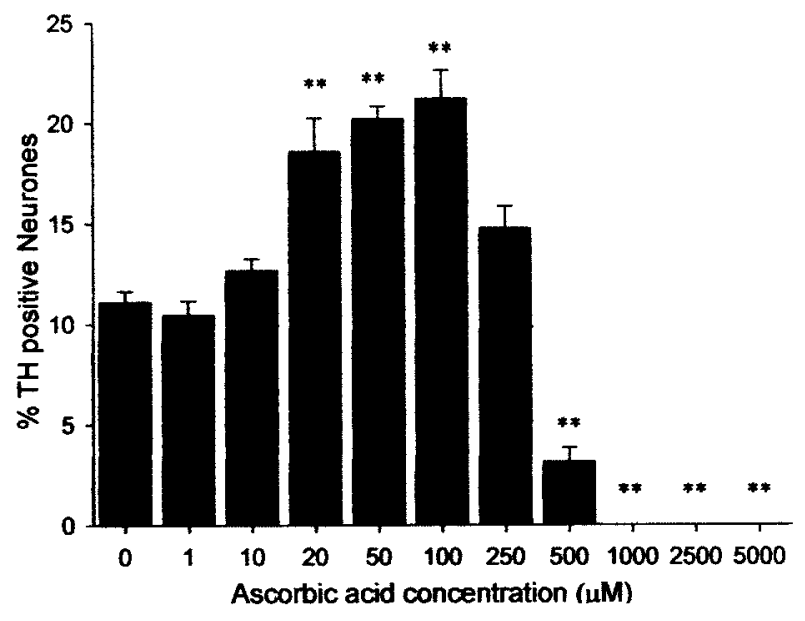

Figure 3. Effect of ascorbic acid concentration on neuronal yield. (A) Effect of dose on total neuronal counts, as determined by $\beta$ III tubulin-positive staining. (B) Effect of dose on percentage of dopamine neurons as determined by TH staining. Data expressed as mean \pm SEM across three separate experiments. $* * p<0.01$ versus $0 \mu \mathrm{M}$. 

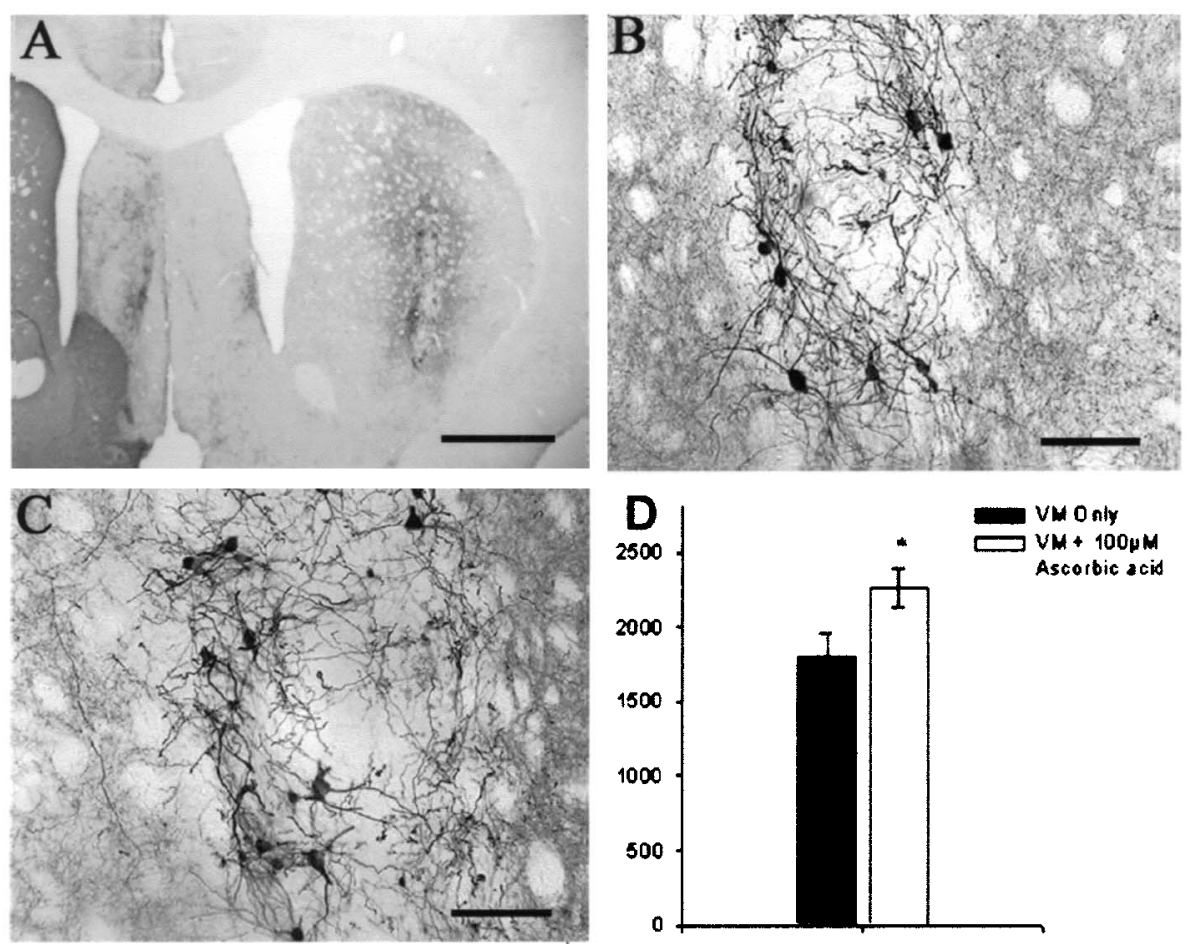

Figure 4. TH immunohistochemical staining of brain sections. (A) Low-magnification image of a representative graft in the striatum. (B) Graft of VM tissue alone. (C) Graft of VM tissue treated with ascorbic acid. Scale bars: (A) $1 \mathrm{~mm},(B, C) 100 \mu \mathrm{m}$. Both graft groups show the presence of many TH neurons. (D) Numbers of TH-positive cells in grafts of VM tissue transplanted in the presence or absence of ascorbic acid. Means \pm SEM. $* p<0.05$.

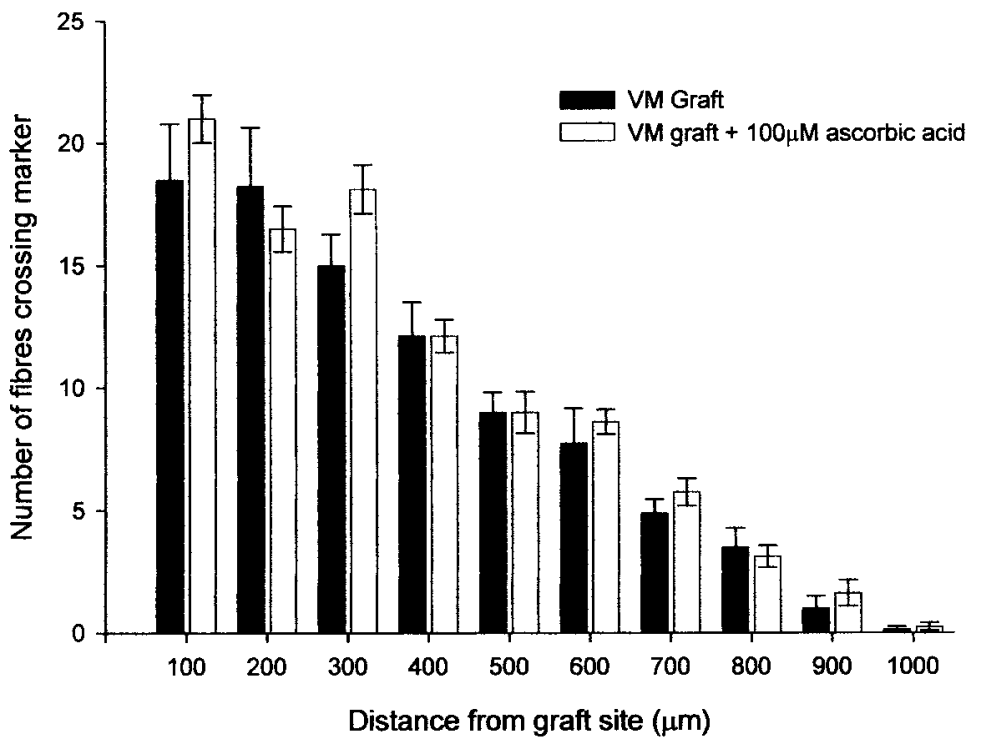

Figure 5. Comparison of graft fiber outgrowth between VM tissue transplanted with and without $100 \mu \mathrm{M}$ ascorbic acid. No significant differences were seen between the two grafted groups. 


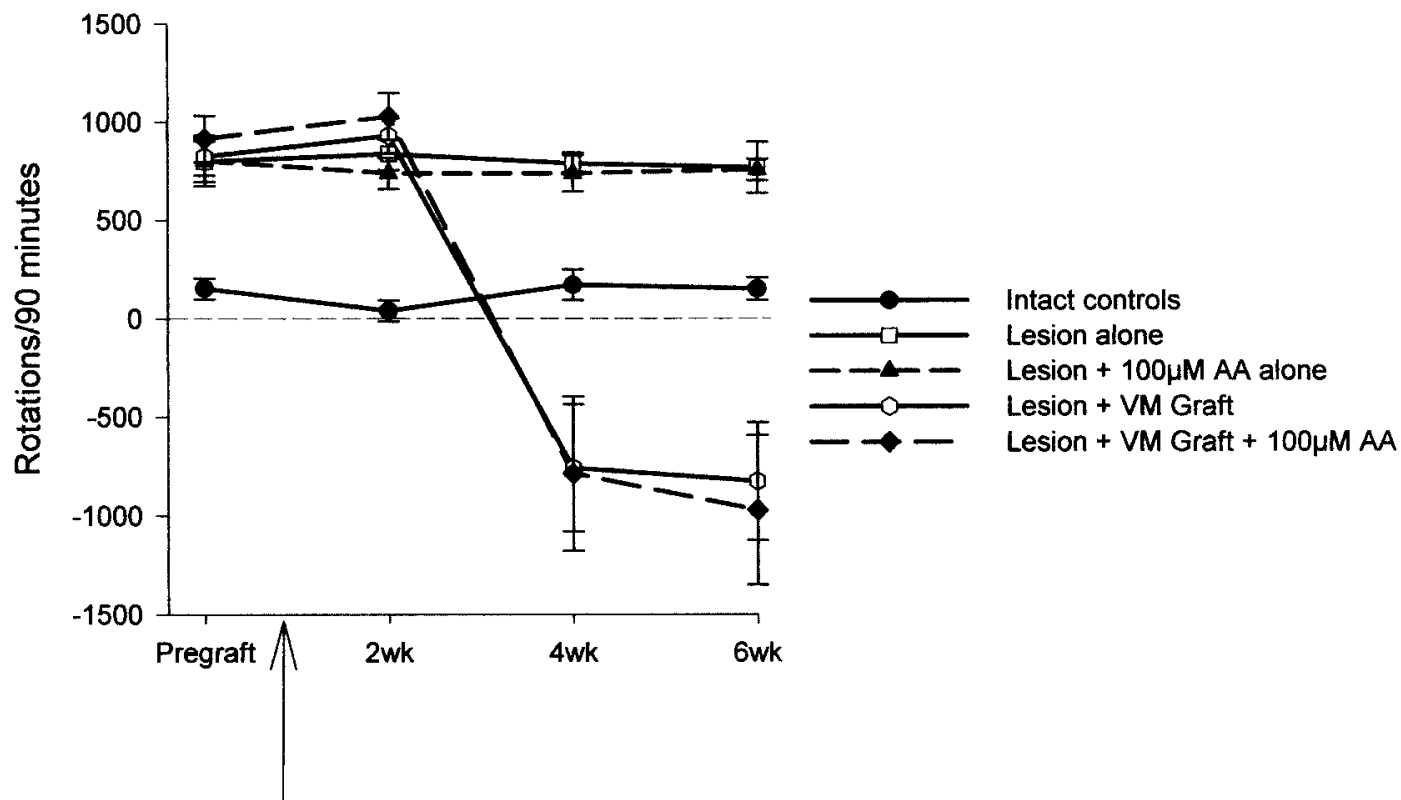

Graft or ascorbic acid administration

Figure 6. Amphetamine-induced rotational behavior. A significant difference in rotational bias with groups is observed ( $p<0.001)$, with both the VM grafted and VM + ascorbic acid groups showing a reduction in rotation at 4 and 6 weeks when compared to pregraft rotation scores. However, no significant difference was observed between these two groups. Lesion-only and ascorbic acidonly groups show no significant difference in rotational behavior. Nonlesioned rats show no significant rotational bias. $* * p<0.01$ versus pregraft scores. Data expressed as mean \pm SEM.

investigated the effects of the antioxidant ascorbic acid on both cultured and transplanted neurons. While ascorbic acid showed no effect on neuronal numbers at low concentrations, ascorbic acid was toxic at higher concentrations. In addition, following ascorbic acid treatment, the number of dopamine neurons derived from VM cells increased significantly both in vitro and in vivo to the 6OHDA rat model of Parkinson's disease.

\section{Effects of Ascorbic Acid on Cell Viability}

Before examining the effects of ascorbic acid on the survival of dopamine neurons, it was important to assess whether ascorbic acid had any general effects on increasing cell viability or cytotoxicity on dissociated mesencephalic cells, and whether this response was dose dependent. Using a trypan blue exclusion assay, the percentage of dead cells was counted following incubation in ascorbic acid at concentrations ranging from 1 to $5000 \mu \mathrm{M}$. Although no cytotoxicity was observed at low concentrations when compared to controls, an increase in cell death was observed at ascorbic acid concentrations of $2500 \mu \mathrm{M}$ and above. Interestingly, when assessing neuronal viability in response to ascorbic acid treatment more severe toxicity was observed in neuronal cultures exposed to a lower concentration of $500 \mu \mathrm{M}$. At this concentration a significant reduction in the percentage of neurons was observed when compared to controls, with higher concentrations resulting in total neuron death. It is surprising that ascorbic acid at these concentrations has adverse effects on neurons because neuronal ascorbic acid levels in vivo are in the region of $10 \mathrm{mM}$ (32). It is possible that the absence of buffering systems in the culture environment resulted in an excessive acidic environment that neurons cannot tolerate. Alternatively, high concentrations of ascorbic acid may favor free radical formation and therefore oxidative stress of cultured neurons. Auto-oxidation of ascorbic acid can generate superoxide free radicals (20) and hydrogen peroxide (12), which damage critical biological molecules. Evidence for this has been shown in cultures of fibroblast cells where the addition of catalase (an enzyme that removes hydrogen peroxide) to fibroblast cells that had been exposed to $300 \mu \mathrm{M}$ ascorbic acid prevented cell death (5). Signs of free radical-mediated damage caused by ascorbic acid have also been shown in vivo where lymphocyte DNA isolated from volunteers whose diets were supplemented with $500 \mathrm{mg}$ of vitamin $\mathrm{C}$ showed increased levels of 8-oxoadenine, a marker for free radical-mediated DNA damage (30).

Together, these studies show that ascorbic acid can produce harmful products capable of damaging cells, and the cytotoxicity of cultured neurons observed in this study is probably due to its pro-oxidant properties. It is important to note that because of the presence of endog- 
enous antioxidants that protect against such oxidative insults, it is unlikely that this toxicity would occur normally in vivo where the neuronal ascorbate concentrations are higher. The difference between the in vivo and in vitro environments suggests that extrapolating conclusions from in vitro data to the in vivo situation must be undertaken with caution.

\section{Increased Expression of Dopamine Neurons Following Treatment With Ascorbic Acid}

Pretreating cultured dopamine neurons with ascorbic acid showed a dose-dependant effect on the expression of TH-positive dopamine neurons. Treatment with concentrations ranging from 20 to $100 \mu \mathrm{M}$ significantly increased the number of dopamine neurons compared with nontreated controls with almost a twofold increase in dopamine neurons being observed. This increase in dopamine neurons following ascorbic acid treatment is consistent with an earlier report that showed increases in dopamine and its primary metabolite 3,4 dihydroxyphenylacetic acid (DOPAC) in cultured mesencephalic neurons following treatment with the same antioxidant (23).

Transplanted cells pretreated with $100 \mu \mathrm{M}$ ascorbic acid also gave rise to a significant increase in the number of TH-positive neurons when compared to nontreated grafts. Although increases in grafted dopamine neurons have not been reported following ascorbic acid treatment alone, similar observations have been reported following ascorbic acid and glutathione treatment (2). Increased numbers of surviving dopamine neurons have also been shown following treatment with different antioxidants and lazaroids $(13,17,25,28)$. Therefore, one mechanism by which ascorbic acid could have increased the number of dopamine neurons in this study is by reducing the likelihood of oxidative stress.

However, although ascorbic acid is a major antioxidant, it also has a variety of other functions, such as being involved in excitatory amino acid release, acting as cofactor in the synthesis of neuropeptides, stimulating myelin formation by Schwann cells, and stimulating acetylcholine and noradrenaline release from synaptic vesicles $(20,23,31)$. Therefore, it is possible that ascorbic acid increased the number of dopamine neurons through another mechanism. A recent report showed that increased numbers of dopamine neurons could be derived from proliferated mesencephalic progenitors treated with ascorbic acid, but that these neurons showed no difference in their expression of markers for oxidative stress when compared to control cultures (38). In addition, no other antioxidants were able to mimic the effect of ascorbic acid in increasing numbers of dopamine neurons. From this it was concluded that ascorbic acid exerts its effects not by acting as an antioxidant and increasing the survival of dopamine neurons, but rather by activating differentiation pathways and promoting the dopaminergic differentiation of neurons (38). Therefore, increased dopaminergic neuron differentiation as opposed to increased survival of dopamine neurons may also explain the increase in dopamine neurons observed in our study, where absolute numbers of neurons were not increased by ascorbic acid treatment, only the proportion of neurons that were dopaminergic. Indeed, a number of recent studies have indicated that the differentiation of dopamine neurons from both neural and embryonic stem cells is enhanced in the presence of ascorbic acid (24, 38). The differentiation of dopamine neurons in rat cortical cell cultures can also be increased by exposing cells to dopamine and subsequent stimulation of dopamine D1 and D2 receptors (40). Therefore, it may be that an ascorbic acid-induced increase in dopaminergic expression is mediated in a similar way, because ascorbic acid can increase the amount of dopamine present, by decreasing dopamine auto-oxidation, and therefore would allow stimulation of D1 and D2 receptors.

\section{Ascorbic Acid Increased Yields of Dopamine Neurons in VM Grafts}

In this study, ascorbic acid treatment of the transplant cell suspensions induced a modest, but significant, 25\% increase in dopamine neurons in the transplants. This is a similar effect to that seen in a previous study treating ventral mesencephalic tissue with a combination of ascorbic acid and glutathione (2). In that study by Agrawal and colleagues, a combination of these ascorbic acid and glutathione, applied for 4 days, led to an $80 \%$ increase in dopamine neuron survival in the grafts, although it is difficult to interpret the functional capacity of these neurons (see below). It is likely that different numbers of surviving neurons reflect differences in methodologies between the two experiments, including: combination of treatments (i.e., the presence of glutathione in addition to ascorbic acid), and time of exposure of the VM cells to treatments. Further studies are being developed to address whether ascorbic acid acts to increase dopaminergic neuron differentiation in the periimplantation period; whether other combinations of differentiation factors and antioxidants can increase both dopamine neuron differentiation and survival in vivo; and the precise cellular mechanisms underlying these responses.

Determination of functional dopamine graft survival following pretreatment with ascorbic acid was assessed by measuring rotational asymmetry in 6-OHDA-lesioned rats. Prior to grafting, only rats displaying at least 600 ipsilateral turns following amphetamine stimulation over the 90 -min testing period were selected, which reflects near total depletion of striatal dopamine (9). Even though 
grafts pretreated with ascorbic acid contained more neurons than nontreated grafts, no difference in rotational bias between graft groups was observed, with both groups showing attenuation and overcompensation of rotational behavior by 6 weeks. This is consistent with an earlier report that showed grafts pretreated with lazaroids contained more dopamine neurons but showed no significant difference in rotation to control grafts 6 weeks posttransplantation (28).

The reason why increased survival of dopamine neurons in pretreated grafts is not reflected in rotational behavior tests is most likely because the control grafts contained enough dopamine cells to reach a ceiling of functional compensation $(6,9)$. Indeed, both graft groups were significantly "overcompensated," at which point any further increases in the number of dopamine cells within grafts has no further effect on rotational behavior (9). Because this saturation point can occur with as few as 300-500 dopamine neurons present (9), and the number of dopamine neurons in both nontreated and treated grafts in our study contained in the region of 2000 dopamine neurons, it is unsurprising that no difference in rotational behavior was observed. For this difference in graft size to be observed in vivo, more complex behavioral tasks should be employed to tease out more subtle differences in dopaminergic reinnervation, such as the lateralized associative learning task recently used by Dowd and Dunnett (14).

In contrast to the data reported here, a recent report by Agrawal and colleagues (2) did show a significant difference in rotational behavior between rats that received either grafts pretreated with glutathione and ascorbic acid or nontreated grafts, even though both graft groups contained enough neurons to reach saturation point. Interestingly, this study also showed increased dopamine cells in the substantia nigra following grafts treated with antioxidants compared to nontreated grafts. No evidence of dopaminergic neurogenesis was observed in cultured nigral cells in our study, and it is unlikely that grafts of dopamine neurons in the striatum would cause neurogenesis of dopamine neurons in the substantia nigra. Instead, it is possible that the difference in rotational bias observed between the groups in that previous study is a result of variable lesioning of the dopamine pathway that has ultimately led to some sparing of nigral dopamine neurons, especially in the cotransplant group. Such an explanation would also account for the improved normalization of dopamine D2 receptor binding and dopamine and DOPAC levels, because the spared dopamine neurons would increase dopamine synthesis as a compensatory mechanism for dopaminergic neuron loss (22).

In conclusion, treatment with ascorbic acid can increase the number of dopaminergic neurons both in vitro and within ventral mesencephalic transplants. Although it is possible to attribute the some of these effects to the antioxidant properties of ascorbic acid, it is also likely that ascorbic acid increases dopaminergic expression in neurons by direct enhancement of dopaminergic differentiation, via as yet unknown mechanisms. To elucidate precisely which mechanisms are involved, further experiments should compare markers of oxidative stress or upregulation of dopamine D1 and D2 receptors after treatment of VM cells with ascorbic acid. In addition, increasing the yield of dopamine neurons using ascorbic acid may prove valuable to improve the functional success of dopamine transplants, increasing their potential as a cell replacement therapy for Parkinson's disease.

ACKNOWLEDGMENTS: This study was supported by a SPRING studentship of the Parkinson's Disease Society (V.B.), a Wellcome Trust Career Development Research Fellowship (R.A.F.G.), and a Medical Research Council program grant (S.B.D.).

\section{REFERENCES}

1. Abercrombie, M. Estimation of nuclear population from microtome sections. Anat. Rec. 94:239-247; 1946.

2. Agrawal, A. K.; Chaturvedi, R. K.; Shukla, S.; Seth, K.; Chauhan, S.; Ahmad, A.; Seth, P. K. Restorative potential of dopaminergic grafts in presence of antioxidants in rat model of Parkinson's disease. J. Chem. Neuroanat. 28: 253-264; 2004.

3. Annett, L. E.; Martel, F. L.; Rogers, D. C.; Ridley, R. M.; Baker, H. F.; Dunnett, S. B. Behavioral assessment of the effects of embryonic nigral grafts in marmosets with unilateral 6-OHDA lesions of the nigrostriatal pathway. Exp. Neurol. 125:228-246; 1994.

4. Annett, L. E.; Torres, E. M.; Clarke, D. J.; Ishida, Y.; Barker, R. A.; Ridley, R. M.; Baker, H. F.; Dunnett, S. B. Survival of nigral grafts within the striatum of marmosets with 6-OHDA lesions depends critically on donor embryo age. Cell Transplant. 6:557-569; 1997.

5. Arakawa, N.; Nemoto, S.; Suzuki, E.; Otsuka, M. Role of hydrogen peroxide in the inhibitory effect of ascorbate on cell growth. J. Nutr. Sci. Vitaminol. (Tokyo) 40:219-227; 1994.

6. Björklund, A.; Dunnett, S. B.; Stenevi, U.; Lewis, M. E.; Iversen, S. D. Reinnervation of the denervated striatum by substantia nigra transplants: Functional consequences as revealed by pharmacological and sensorimotor testing. Brain Res. 199:307-333; 1980.

7. Björklund, A.; Dunnett, S. B. Dopamine neuron systems in the brain: An update. Trends Neurosci. 30:195-202; 2007.

8. Brundin, P.; Isacson, O.; Gage, F. H.; Prochiantz, A.; Björklund, A. The rotating 6-hydroxydopamine-lesioned mouse as a model for assessing functional effects of neuronal grafting. Brain Res. 366:346-349; 1986.

9. Brundin, P.; Barbin, G.; Strecker, R. E.; Isacson, O.; Prochiantz, A.; Björklund, A. Survival and function of dissociated rat dopamine neurones grafted at different developmental stages or after being cultured in vitro. Brain Res. 467:233-243; 1988.

10. Brundin, P.; Björklund, A. Survival of expanded dopamin- 
ergic precursors is critical for clinical trials. Nat. Neurosci. 1:537; 1998.

11. Brundin, P.; Karlsson, J.; Emgard, M.; Schierle, G. S.; Hansson, O.; Petersen, A.; Castilho, R. F. Improving the survival of grafted dopaminergic neurones: A review over current approaches. Cell Transplant. 9:179-195; 2000.

12. Clement, M. V.; Ramalingam, J.; Long, L. H.; Halliwell, B. The in vitro cytotoxicity of ascorbate depends on the culture medium used to perform the assay and involves hydrogen peroxide. Antioxid. Redox. Signal. 3:157-163; 2001.

13. Colton, C. A.; Pagan, F.; Snell, J.; Colton, J. S.; Cummins, A.; Gilbert, D. L. Protection from oxidation enhances the survival of cultured mesencephalic neurones. Exp. Neurol. 132:54-61; 1995.

14. Dowd, E.; Dunnett, S. B. Deficits in a lateralized associative learning task in dopamine-depleted rats with functional recovery by dopamine-rich transplants. Eur. J. Neurosci. 20:1953-1959; 2004.

15. Dunnett, S. B. Transplantation of dopamine neurones. Semin. Neurosci. 4:161-169; 1992.

16. Fahn, S.; Cohen, G. The oxidant stress hypothesis in Parkinson's disease: Evidence supporting it. Ann. Neurol. 32: 804-812; 1992.

17. Frodl, E. M.; Nakao, N.; Brundin, P. Lazaroids improve the survival of cultured rat embryonic mesencephalic neurones. NeuroReport 5:2393-2396; 1994.

18. German, D. C.; Manaye, K. F. Midbrain dopaminergicneurons (nuclei A8, A9, and A10): 3-dimensional reconstruction in the rat. J. Comp. Neurol. 331:297-309; 1993.

19. Grasbon-Frodl, E. M.; Andersson, A.; Brundin, P. Lazaroid treatment prevents death of cultured rat embryonic mesencephalic neurones following glutathione depletion. J. Neurochem. 67:1653-1660; 1996.

20. Grunewald, R. A. Ascorbic acid in the brain. Brain Res. Rev. 18:123-133; 1993.

21. Hagell, P.; Cenci, M. A. Dyskinesias and dopamine cell replacement in Parkinson's disease: A clinical perspective. Brain Res. Bull. 68:4-15; 2005

22. Hefti, F.; Melamed, E.; Sahakian, B. J.; Wurtman, R. J. Circling behavior in rats with partial, unilateral nigro-striatal lesions: Effect of amphetamine, apomorphine, and DOPA. Pharmacol. Biochem. Behav. 12:185-188; 1980.

23. Kalir, H. H.; Mytilineou, C. Ascorbic acid in mesencephalic cultures: Effects on dopaminergic neurone development. J. Neurochem. 57:458-464; 1991.

24. Lau, T.; Adam, S.; Schloss, P. Rapid and efficient differentiation of dopaminergic neurons from mouse embryonic stem cells. NeuroReport 17:975-979; 2006.

25. Love, R. M.; Branton, R. L.; Karlsson, J.; Brundin, P.; Clarke, D. J. Effects of antioxidant pretreatment on the survival of embryonic dopaminergic neurones in vitro and following grafting in an animal model of Parkinson's disease. Cell Transplant. 11:653-662; 2002.

26. Low, W. C.; Triarhou, L. C.; Kaseda, Y.; Norton, J.;
Ghetti, B. Functional innervation of the striatum by ventral mesencephalic grafts in mice with inherited nigrostriatal dopamine deficiency. Brain Res. 435:315-321; 1987.

27. Maries, E.; Kordower, J. H.; Chu, Y.; Collier, T. J.; Sortwell, C. E.; Olaru, E.; Shannon, K.; Steece-Collier, K. Focal not widespread grafts induce novel dyskinetic behavior in parkinsonian rats. Neurobiol. Dis. 21:165-180; 2006.

28. Nakao, N.; Frodl, E. M.; Duan, W. M.; Widner, H.; Brundin, P. Lazaroids improve the survival of grafted rat embryonic dopamine neurones. Proc. Natl. Acad. Sci. USA 91:12408-12412; 1994.

29. Olanow, C. W. A radical hypothesis for neurodegeneration. Trends Neurosci. 16:439-444; 1993.

30. Podmore, I. D.; Griffiths, H. R.; Herbert, K. E.; Mistry, N.; Mistry, P.; Lunec, J. Vitamin C exhibits pro-oxidant properties. Nature 392:559; 1998.

31. Rice, M. E.; Russo-Menna, I. Differential compartmentalization of brain ascorbate and glutathione between neurones and glia. Neuroscience 82:1213-1223; 1998.

32. Rice, M. E. Ascorbate regulation and its neuroprotective role in the brain. Trends Neurosci. 23:209-216; 2000.

33. Sian, J.; Dexter, D. T.; Lees, A. J.; Daniel, S.; Agid, Y.; Javoy-Agid, F.; Jenner, P.; Marsden, C. D. Alterations in glutathione levels in Parkinson's disease and other neurodegenerative disorders affecting basal ganglia. Ann. Neurol. 36:348-355; 1994

34. Sirinathsinghji, D. J.; Dunnett, S. B.; Northrop, A. J.; Morris, B. J. Experimental hemiparkinsonism in the rat following chronic unilateral infusion of MPP+ into the nigrostriatal dopamine pathway III. Reversal by embryonic nigral dopamine grafts. Neuroscience 37:757-766; 1990.

35. Storch, A.; Paul, G.; Csete, M.; Boehm, B. O.; Carvey, P. M.; Kupsch, A.; Schwarz, J. Long-term proliferation and dopaminergic differentiation of human mesencephalic neural precursor cells. Exp. Neurol. 170:317-325; 2001.

36. Studer, L.; Csete, M.; Lee, S. H.; Kabbani, N.; Walikonis, J.; Wold, B.; McKay, R. Enhanced proliferation, survival, and dopaminergic differentiation of CNS precursors in lowered oxygen. J. Neurosci. 20:7377-7383; 2000.

37. Ungerstedt, U.; Arbuthnott, G. W. Quantitative recording of rotational behavior in rats after 6-hydroxy-dopamine lesions of the nigrostriatal dopamine system. Brain Res. 24: 485-493; 1970.

38. Yan, J.; Studer, L.; McKay, R. D. Ascorbic acid increases the yield of dopaminergic neurones derived from basic fibroblast growth factor expanded mesencephalic precursors. J. Neurochem. 76:307-311; 2001.

39. Zawada, W. M.; Zastrow, D. J.; Clarkson, E. D.; Adams, F. S.; Bell, K. P.; Freed, C. R. Growth factors improve immediate survival of embryonic dopamine neurones after transplantation into rats. Brain Res. 786:96-103; 1998.

40. Zhou, J.; Bradford, H. F.; Stern, G. M. Induction of dopaminergic neurotransmitter phenotype in rat embryonic cerebrocortex by the synergistic action of neurotrophins and dopamine. Eur. J. Neurosci. 8:2328-2339; 1996. 
